\title{
Risky sexual practice, unintended pregnancy, contraceptive utilisation, and its determinants among HIV-infected women in Special Zone of Oromia regional state, Ethiopia
}

Dereje Bayissa Demissie ( $\square$ dereje.bayissa@sphmmc.edu.et)

St. Paul's Hospital Millennium Medical College https://orcid.org/0000-0003-1006-4318

Rose Mmusi-Phetoe

UNISA

\section{Research}

Keywords: Risky sexual practice, unintended pregnancy, condom utilisation, contraceptive utilisation, women living with HIV

Posted Date: February 5th, 2021

DOl: https://doi.org/10.21203/rs.3.rs-183560/v1

License: (1) (1) This work is licensed under a Creative Commons Attribution 4.0 International License.

Read Full License 


\section{Abstract}

Background: In settings where HIV prevalence is high, management of sexual and reproductive health is critical to reducing HIV transmission and maternal mortality. Integration of family planning with HIV services is appropriate model for HIV therapy, HIV prevention and care with family planning services in a resource limiting area like Ethiopia. The aims of the study were to determine risky sexual practice, unintended pregnancy, contraceptive utilisation, and its determinants among women of reproductive age in Oromia, Ethiopia

Methods: A Health facility based cross-sectional study design was conducted with quantitative data collection approach was used to collect data from women living with HIV attending ART clinics in special zone of surrounding Finfinne, Oromia Region in five health centres. Simple random sampling computergenerated sample was used to select 654 respondents. The returned questionnaires were checked for completeness, cleaned manually, coded and entered into EPI INFO 7.1.6 version and exported to SPSSS 23.0 for further analysis. Bivariate and multivariable logistic regressions analysis was used to identify factors association with adjusted odds ratio (AOR) with 95\% confidence interval (Cl) to controlled effects of possible confounders from final model.

Result: After discarded 16 spoiled questionnaires, the completed response rate of this study was $97.6 \%$ $(654 / 670)$. There were 654 respondents whose ages ranged between 18 and 49 years. The current family planning utilisation among women of reproductive age living with HIV was 548 (83.8\%). The following were identified as determinants of current family planning among HIV-infected women in the area of study: open discussion on modern family planning utilisation with healthcare providers; being knowledgeable about modern family planning; number of sexual partners; previous unplanned pregnancy; partner's HIV status; and disclosure status of HIV to their family. The last two factors led to higher odds of family planning utilisation among women of reproductive age living with HIV in Oromia Region.

The study further established that contraception utilisation was influenced by the fact that 608 (94.9\%) respondents were sexually active during the last six months. Disclosure of HIV status added to the list whereby $589(91.4 \%)$ respondents had disclosed their HIV serostatus to a regular sexual partner and 499 $(76.3 \%)$ had disclosed to family.

The prevalence of dual contraceptive utilisation was 425 (73.8\%), of which $343(80.7 \%)$ and $306(72 \%)$ were consistent and sustained users of dual contraceptive methods, respectively. The factors which were assumed to be increasing dual contraception method utilisation were: open discussion on family planning with healthcare providers; having received family planning counselling about the efficacy of each method and side effects and the mixed method available.

Conclusion: The current family planning utilisation among women of reproductive age was higher than the national contraceptive prevalence rate. This proportion is parallel to the proportion of service providers reporting to provide both HIV- and family planning-related services as being largely dependent on training on integrated family planning and HIV services. 


\section{Introduction}

HIV infection is a pandemic disease. Globally, about 35 million individuals were living with HIV in 2013. Of these, 24.7 million were in sub-Saharan Africa and 4.8 million in Asia and the Pacific (UNAIDS 2014:131). In 2013, about 16 million individuals living with HIV globally were women aged 15 years and older, and 3.2 million were children under 15 years of age (UNAIDS 2014:120). More than $90 \%$ of HIVpositive pregnant women reside in sub-Saharan Africa (Kendall \& Danel 2014:48-49). In 2013, 1.5 million HIV-infected women gave birth globally and there were 240000 new paediatric infections, amounting to one new infection every two minutes (UNAIDS 2014:120-131). HIV is thus the leading cause of death in women of reproductive age globally; it is responsible for one-quarter of deaths during pregnancy and in the postpartum period in sub-Saharan Africa (Kendall \& Danel 2014:48-49).

The two top causes of death in women of reproductive age globally are HIV and AIDS (19\%) and complications related to childbearing (15\%) (WHO, USAID \& FHI 2009:43).Sub-Saharan Africa has the highest maternal mortality ratio, reporting levels of 596 deaths per 100,000 live births (Hogan, Foreman, Naghavi, Ahn, Wang, Makela\& Murray2010:1609). Further, half of the global maternal deaths occur in the sub-Saharan region. There seems to be a need to suggest strategies that are evidence-based to integrate family planning services with HIV treatment among women who are living with HIV. This may prevent treatable complications among them and their children, which lead to public health concerns in terms of high preventable childbearing complications and morbidity due to HIV/AIDS. The findings of this study informed the development of strategies to integrate family planning services with HIV services in Oromia Region, Ethiopia, and provided evidence-based input for policymakers and health planners.

\section{Statement of the problems}

There were beneficial synergies in terms of increased 'sexually transmitted infection' (STI) prevention, including syphilis screening and treatment, and early childhood immunisation (Nutman, McKee \& Khoshnood 2013:445-460). Another peer-reviewed study illustrated how best to integrate other interventions, such as postpartum contraception or tuberculosis screening and treatment, into services that are already providing some parts of integrated HIV care for pregnant and postpartum women, which is almost non-existent (Tudor-Car, Van-Velthoven, Brusamento, Elmoniry, Car, Majeed \& Atun 2011:9).

Dual protection is the prevention of two unplanned and undesirable outcomes- unintended pregnancy and HIV infection- and may be achieved through the use of contraception in long-term, mutual, monogamous relationships. Alternatively, it includes the use of a condom, plus another non-barrier contraceptive method, or the use of a condom alone (including during pregnancy), abstinence, or avoidance of all types of penetrative sex (Orner, De Bruyn, Barbosa, Boonstra, Gatsi-Mallet \& Cooper2011:54). One of the most important advantages to 'integrating family planning with HIV services' is the potential contribution of contraception to prevent unintended HIV-positive births, which has been well established through extensive research (Hladik, Stover, Esiru, Harper\&Tappero 2009:e7691; Reynolds, Toroitich-Ruto, Nasution, Beaston-Blaakman \& Janowitz 2008:56-66; Halperin, Stover\& Reynolds 
2009:S123-S130). Integrating family planning with HIV treatment has presented evidence on HIV-positive women's desire to prevent unwanted pregnancies (Johnson, Akwara, Rutstein\& Bernstein 2009:S12; Wanyenze, Tumwesigye, Kindyomunda, Beyeza-Kashesya, Atuyambe, Kansiime \& Mirembe 2011:35). Notable research findings showed evidence that preventing unwanted pregnancies to HIV-positive women reduce infant HIV infections, thus the policy for integration is sound (Wanyenze et al 2011:35).

Like all women, women living with and at risk of acquiring HIV have the right to determine the number and timing of their pregnancies and safely achieve their reproductive intentions(Mahy, Stover, Kiragu, Hayashi, Akwara, Luo \& Shaffer2010:53). A systematic review evidenced from Africa revealed that providing concerted information and support on family planning utilisation and ready-to-access contraceptive methods seemed most effective in increasing the use of family planning, while the effects on unplanned pregnancy were difficult to measure. However, no studies assessed the effects of family planning on unintended pregnancy (O'Reilly, Kennedy, Fonner \& Sweat2013:935). This review indicated that the results are far from definitive, yet they do highlight the need for strengthened efforts to integrate family planning counselling and access to services for HIV prevention, and for greater consistency of effort over time (O'Reillyet al2013:935). Programmes that have succeeded in promoting condom use and providing HIV prevention and treatment services in this region have largely missed the opportunity to address the contraceptive needs of the key populations they serve. Therefore, the research statement for this study is "What are status of Risky sexual practice, unintended pregnancy, contraceptive utilisation, and its determinants among HIV-infected women for women of reproductive age living with HIV attending healthcare facilities in Oromia Region, Ethiopia?"

\section{Materials And Methods}

\section{Research Setting and design}

This study was conducted in the Oromia Region surroundings of Finfinne Oromia, Ethiopia. Currently, the health system of the zone consists of two hospitals under construction, and 27 health centres with $98 \%$ potential health service coverage. There were different governmental and non-governmental organisations working on HIV/AIDS in the zone. There were 13 health centres which have been providing ART and family planning services in the zone, of which five were randomly selected as the study setting. The total number of people living with HIV enrolled at ART clinics in the zone was 9421, of which 2380 were women of reproductive age, and of these, 1557 were from five randomly selected health centres (Office Finfinne Special Zone 2018:6). The target population was HIV-positive women of reproductive age who had attended ART follow-up services for at least six months from randomly selected healthcare facilities in Oromia Region, Ethiopia. The accessible sample was 1557 eligible women of reproductive age living with HIV attending ART clinics in public health centres.

A Health facility based cross-sectional study design was conducted with quantitative data collection approach was used to collect data from women living with HIV attending ART clinics

\section{Sample size determination}


The sample size was determined through a single population proportion formula by using a case study found in integrated sites in Ethiopia, where $40 \%$ of women were family planning users $(P)$ (Scholl \& Cothran 2011:9). By considering the design effect of 2, with correction formula since the total population was less than 10000 (2380) and with a 5\% non-response rate considered, the final sample size was 670 women living with HIV.

\section{Sampling procedure}

All hospitals and health centres found in the Special Zone of Oromia Region that provide ART services were identified and randomly selected by computer-generated methods to be included in the study. A list of all women living with HIV from each facility, aged between 18 years and 49 years of age, was randomly created. Study sites were prepared and entered into SPSS version 23 by using their pre-ART registration numbers from the health management information system (HMIS) database. A simple random sampling technique by computer-generated samples was utilised at each health centre to select 670 study respondents. The number of study respondents was allocated proportionally for the five health centres, based on their total number of ART clients.

\section{Data collection}

The questionnaire used for data collection was initially prepared in English, and translated to Afan Oromo, and back to English for language experts to confirm its consistency. Finally, the corrected Afan Oromo version was used to collect the data from women living with HIV attending ART clinics. The questions included in the questionnaire were adapted and prepared by reviewing different related literature and variables identified to be measured. Training was given for data collectors and supervisors by the primary researcher for two days. Data collectors cross-checked the pre-ART card numbers of women living with HIV who came to the ART clinic with sampled card numbers daily. Five trained data collectors collected data from women of reproductive age. The completed questionnaires were collected and checked daily for consistency and completeness by supervisors and the primary researcher. Data were collected using a pre-tested structured Afan Oromo version of the questionnaire. A pre-test of the questionnaire was done on $5 \%$ of the women living with HIV at Ambo health centre, to identify any ambiguity, to confirm consistency in the questionnaire, to determine acceptability, and to make necessary corrections one week before the actual data collection process. The respondents were guided through a questionnaire and chart abstraction conducted at their health facility by trained data collectors.

\section{Data management and analysis}

The returned questionnaires were checked for completeness, cleaned manually, coded and entered into EPI INFO 7.1.6 version and then transferred to SPSS version 23 for further analysis. Frequencies, percentages, mean and standard deviation (SD) were used to summarise descriptive statistics of the data and text. Moreover, tables and graphs will be used for data presentation. Bivariate analysis was used primarily to check which variables have an individual association with the dependent variable. Variables which were found to have an association with the dependent variables were then entered into multiple logistic regressions to control the possible effect of confounders. Finally, the variables which have 
significant association were identified on the basis of $A O R$, with a $95 \% \mathrm{Cl}$ and p-value to fit into the final regression model.

\section{Ethical Consideration}

The rights of the institution were protected by obtained ethical clearance (Ref.No HSHDC/710/2017) from the Research and Ethics Committee of the Department of Health Studies at the UNISA. Thereafter, a letter of permission to conduct this research was also obtained from the ORHB who requested support for the researcher from each study site to facilitate the data collection process (Ref.No BEFO/HBT64/18/2569). Written consent was obtained from each study participant, after the nature of the study was fully explained in their local languages as it was attached in the questionnaire. The respondents' right to refuse or withdraw from the study at any stage was respected. Information collected from respondents was kept confidential, and the collected information was stored in a locked space, in a file without the name of the study respondent (anonymously), but codes were assigned for each respondent and have not been disclosed to others except the principal investigators. Scientific integrity was ensured by avoiding plagiarism, being honest in reporting on the findings, and accurately citing all consulted sources.

\section{Results}

The complete response rate of this study was $654 / 670$ (97.6\%).

There were 654 respondents whose ages ranged between 18 and 49 years. The mean age of the respondents was 31.86 years with a SD of \pm 6.0 years. Most of the respondents in the sample were in the age group $26-35(n=374,57 \%)$, and only $96(14.7 \%)$ were in the age group $18-25$. Of the $14.7 \%, 4(0.6 \%)$ were younger than 20 years.

In terms of religious affiliation, $474(72.5 \%)$ respondents belonged to the orthodox denomination, $7(1.1 \%)$ were Catholic, while 131 (20\%) were Protestants and 42 (6.4\%) were Muslims.

The majority ( $n=409,62.5 \%)$ of the respondents had at least attended school from primary level to college/university level, and the least represented were $19(2.9 \%)$ who had attained tertiary level education in the form of attending a college or university.

As presented in Table 1, 528 (88.5\%) respondents were married, 51 (7.1\%) were cohabiting/living together with their partners, while $7(1.1 \%)$ were single. The other women were divorced or separated and widowed. The marital status of respondents is presented in Table 1. 
Table 1

Proportion of women by marital status in Oromia Region, Ethiopia, 2018

\begin{tabular}{|ll|}
\hline Marital Status & Frequency (\%) \\
\hline Married & $528(80.7)$ \\
\hline Cohabit/living together ${ }^{*}$ & $51(7.8)$ \\
\hline Divorced/separated & $46(7.0)$ \\
\hline Widowed & $22(3.4)$ \\
\hline Single & $7(1.1)$ \\
\hline Total & $654(100)$ \\
\hline *Living together with a partner without legal marriage certification \\
\hline
\end{tabular}

With regard to the residential area, the majority of the respondents ( $n=518,79.2 \%)$, resided in urban areas, and $136(20.8 \%)$ lived in the rural area. The socioeconomic characteristics of the respondents as summarised in Table 1 are not different from the socioeconomic profile of Ethiopia. For example, in the general population of the same region, Christian denominations dominate and represent $65 \%$ of the population, and the largest ethnic group is Oromo, followed by Amhara which represent $64 \%$ of the population (CSA 2016:33). The results are also similar in terms of the proportion of women who are currently married or living together with a partner (65\%) in the general population (CSA 2016:34).

\section{Risky sexual practice, condom utilisation, and unintended pregnancy}

The findings on risky sexual practice, condom utilisation, and unintended pregnancy among women of reproductive age living with HIV are presented in Table 2. 
Table 2

Risky sexual practice, condom utilisation, and unintended pregnancy among women of reproductive age living with HIV in Oromia, Ethiopia 2018

\begin{tabular}{|c|c|c|}
\hline $\begin{array}{l}\text { Risky sexual practice, condom utilisation, and } \\
\text { unintended pregnancy }\end{array}$ & Category of responses & $\begin{array}{l}\text { Frequency } \\
(\%)\end{array}$ \\
\hline \multirow[t]{2}{*}{ Have partner $(n=654)$} & Yes & $641(98.0)$ \\
\hline & No & $13(2.0)$ \\
\hline \multirow[t]{2}{*}{ Had sex in the last 6 months $(n=654)$} & Yes & $608(94.9)$ \\
\hline & No & $33(5.1)$ \\
\hline \multirow{2}{*}{$\begin{array}{l}\text { Number of sexual partners had in the last } 6 \\
\text { months }(n=641)\end{array}$} & One & $608(94.9)$ \\
\hline & Two and above & $33(5.1)$ \\
\hline \multirow[t]{2}{*}{ Condom use in the last six months $(n=630)$} & Yes & $451(71.6)$ \\
\hline & No & $179(28.4)$ \\
\hline \multirow{3}{*}{$\begin{array}{l}\text { Frequency of condom use during sexual } \\
\text { intercourse }\end{array}$} & Always & $279(61.9)$ \\
\hline & Almost always & $66(14.6)$ \\
\hline & No/inconsistent condom use & 106(23.5) \\
\hline \multirow[t]{3}{*}{ Reason for not using a condom $(n=179)$} & $\begin{array}{l}\text { felt some discomfort or reduced } \\
\text { sexual pleasure }\end{array}$ & $70(39.1)$ \\
\hline & Partner objection & $68(38.0)$ \\
\hline & Desire to conceive & $41(22.9)$ \\
\hline \multirow[t]{3}{*}{ Partner HIV-positive } & Yes & $481(73.5)$ \\
\hline & No & $105(16.1)$ \\
\hline & Unknown & $68(10.4)$ \\
\hline \multirow[t]{2}{*}{ Changed sexual partners since HIV diagnosis } & Yes & $174(26.6)$ \\
\hline & No & $480(73.4)$ \\
\hline \multirow[t]{2}{*}{ Last pregnancy wanted/timed } & Yes & 514 \\
\hline & No & 140 \\
\hline \multirow[t]{2}{*}{ Have children in the future/fertility desire } & Yes & 324 \\
\hline & No & 330 \\
\hline
\end{tabular}

Table 2 illustrates that of a total of 654 respondents, almost all of them $(n=641,98.0 \%)$ had a sexual partner. Of these, $33(5.1 \%)$ had two or more sexual partners in the last six months and $174(26.6 \%)$ had changed sexual partners since their HIV diagnosis. 
The result also indicated that $608(94.9 \%)$ respondents were sexually active during the last six months; however, only 279 (61.9\%) always used a condom; 105 (16.1\%) were discordant in HIV serostatus, and 68 (10.4\%) did not know their sexual partners' HIV serostatus.

The proportion of condom utilisation in the last six months was reported by 451 (71.6\%) respondents, although 106 (23.5\%) were inconsistent.

The findings revealed that the major reasons for not using a condom were that the respondents felt some discomfort or sexual pleasure was reduced; their partner objected to the use of a condom, and some had the desire to conceive a baby; 70 (39.1\%), 68 (38\%), and 41 (22.9\%), respectively.

These results identified that $140(21.4 \%)$ respondents' previous pregnancy was unwanted/unplanned, and $324(49.5 \%)$ had fertility desire. Table 2.

\section{HIV therapy and disclosure of HIV status}

The mean years since HIV diagnosis were 5.64 with $\mathrm{a} \pm$ Std. deviation of 2.777 and all the respondents had started ART, of which $36.9 \%$ were greater than or equal to 6 years, with a mean of $4.90 \pm$ Std. deviations of 2.577 in years since they started ART.

According to client cards, study respondents' ART drug adherence level indicated that the majority $(\mathrm{n}=$ $576,88.1 \%)$ had good and 38 (5.8\%) had poor adherence towards ART drugs in the study area. From a total of 654 women of reproductive age living with HIV attending ART follow up, about $439(67.1 \%)$ had a baseline CD4 count less than 350 cells $/ \mathrm{mm}^{3}$ with an average CD4 count of $316.60 \pm$ Std. deviation 224.796 cells $/ \mathrm{mm}^{3}$, but their recent $\mathrm{CD}_{4}$ count after initiating ART drugs in the last six months revealed that $330(50.5 \%)$ of the respondents had greater than or equal to $500 \mathrm{cells} / \mathrm{mm}^{3}$ with an average CD4 count of $541.92 \pm$ Std. deviation 265.823 cells $/ \mathrm{mm}^{3}$.

The WHO stage classification during enrolment to ART/PMTCT programmes showed that $275(42.0 \%)$ were stage one as evidenced from client records. Of the total study respondents of 654, $589(91.4 \%)$ and 499 (76.3\%) disclosed their HIV serostatus to their regular sexual partner and family, respectively (See Table 3). 
Table 3

HIV therapy and disclosure of HIV status of women of reproductive age living with HIV in Oromia, Ethiopia 2018

\section{HIV therapy and disclosure}

Duration since HIV diagnosis in years $(n=654)$

Mean $5.64 \pm$ Std. Deviation of 2.78 years

Duration since started ART in years $(n=654)$

Mean $4.90 \pm$ Std. Deviation 2.577

Started ART $(n=654)$ :
ART drug adherence level according to client
Baseline CD4 count in cells $/ \mathrm{mm}^{3}(n=654)$

Mean $316.60 \pm$ Std. Deviation 224.796
Category

$<3$ years

3 to 5 years

$>=6$ years

$<=3$ years

3.1 to 6 years

$>=6$ years

Yes

No

Good

Fair

Poor

$<350$ cells $/ \mathrm{mm}^{3}$

$350-500$

cells $/ \mathrm{mm}^{3}$

$>500$ cells $/ \mathrm{mm}^{3}$

$<350$ cells $/ \mathrm{mm}^{3}$

350-500

cells $/ \mathrm{mm}^{3}$

Mean 541.92 \pm Std. Deviation 265.823

654)

(a)
WHO stage enrolment according to client record $(n=654)$

$>500$ cells $/ \mathrm{mm}^{3}$

Stage 1

Stage 2

Stage 3

Stage 4

Disclosure of HIV status to regular partner:

Disclosure HIV status to the family

\begin{tabular}{ll} 
Yes & $598(91.4)$ \\
No & $56(8.6)$ \\
\hline Yes & $499(76.3)$
\end{tabular}

Frequency

(\%)

177(27.1)

159(24.3)

318(48.6)

224

189

241

654(100.0)

$0(0.0)$

$576(88.1)$

40(6.1)

$38(5.8)$

439(67.1)

113(17.3)

102(15.6)

164(25.1)

160(24.5)

$330(50.5)$

275(42.0)

226(34.6)

138(21.1)

15(2.3)

$56(8.6)$

499(76.3) 
Table 4

Family planning and dual method utilisation of women of reproductive age living with HIV in Oromia, Ethiopia 2018

\begin{tabular}{|c|c|c|c|}
\hline Family planning utilisations & Responses & Frequency (\%) & $95 \%(\mathrm{Cl})$ \\
\hline \multirow[t]{2}{*}{ Current family planning utilisation } & Yes & $548(83.8)$ & $\begin{array}{l}81.2- \\
86.8\end{array}$ \\
\hline & No & 106(16.2) & $\begin{array}{l}13.2- \\
18.8\end{array}$ \\
\hline \multirow{2}{*}{$\begin{array}{l}\text { Use contraceptive methods in addition to Condom } \\
\text { (dual contraceptive use) }\end{array}$} & Yes & $425(73.8)$ & $70.0-77.3$ \\
\hline & No & $151(26.2)$ & $\begin{array}{l}22.7- \\
30.0\end{array}$ \\
\hline \multirow[t]{2}{*}{ Consistently use the dual methods $(\mathrm{N}=425)$} & Yes & $343(80.7)$ & $\begin{array}{l}76.7- \\
84.2\end{array}$ \\
\hline & No & 82(19.3) & $\begin{array}{l}15.8- \\
23.3\end{array}$ \\
\hline \multirow[t]{2}{*}{ Sustain use of dual methods $(\mathrm{N}=425)$} & Yes & $306(72.0)$ & $\begin{array}{l}67.5- \\
76.5\end{array}$ \\
\hline & No & $119(28.0)$ & $\begin{array}{l}23.5- \\
32.5\end{array}$ \\
\hline \multirow[t]{4}{*}{$\begin{array}{l}\text { Reason for dual contraceptive use/ use contraceptive } \\
\text { methods in addition to condom }\end{array}$} & \multicolumn{2}{|c|}{$\begin{array}{l}\text { Dual protection (unwanted } \\
\text { pregnancy/STI/HIV) }\end{array}$} & $386(90.8)$ \\
\hline & \multicolumn{2}{|c|}{$\begin{array}{l}\text { with new strain to protect a } \\
\text { negative partner }\end{array}$} & $13(3.1)$ \\
\hline & \multicolumn{2}{|c|}{ Advice by health workers } & $20(4.7)$ \\
\hline & \multicolumn{2}{|c|}{ Fear of re-infection } & $6(1.4)$ \\
\hline \multirow{3}{*}{$\begin{array}{l}\text { Discussed with a partner about dual contraceptive } \\
\text { utilisation }\end{array}$} & \multicolumn{2}{|l|}{ Yes } & $427(65.3)$ \\
\hline & \multicolumn{2}{|l|}{ No } & $220(33.6)$ \\
\hline & \multicolumn{2}{|c|}{ Have no partner } & $7(1.1)$ \\
\hline \multirow{2}{*}{$\begin{array}{l}\text { Discussed with healthcare providers about dual } \\
\text { contraceptive utilisation }\end{array}$} & \multicolumn{2}{|l|}{ Yes } & $543(83.0)$ \\
\hline & \multicolumn{2}{|l|}{ No } & $111(17.0)$ \\
\hline
\end{tabular}

Family planning and dual contraceptive utilisations 
Family planning is a programme to regulate the number and spacing of children in a family through the practice of contraception or other forms of birth control (UNAIDS 2015:42). The dual conceptive method is the prevention of two unplanned and undesirable outcomes, namely unintended pregnancy by use of contraception in a long-term mutually monogamous relationship. This includes the use of a condom plus another non-barrier contraceptive method, the use of a condom alone (including during pregnancy), abstinence or avoidance of all types of penetrative sex (Orner et al 2011:54). One of the most important advantages to integrating family planning and HIV services is the potential contribution of contraception to prevent unintended HIV-positive births, which has been well established through extensive research (Hladiket al2009:7691).

\section{Knowledge about modern family planning}

These measurement variables were related to knowledge about modern family planning methods.

Figure 1 shows that more than half $(n=374,57.2 \%)$ of the respondents had good knowledge of modern family planning methods. The proportion of good knowledge regarding the eleven measurement variables of modern family planning methods among women of reproductive age living with HIV ranged from $53.5-60.9 \%$, with $95 \% \mathrm{Cl}$.

The results in Fig. 2 should be viewed within the context of education characteristics of the respondents and their knowledge and awareness of modern family planning methods. For instance, as the educational status of the women increased, their knowledge towards family planning methods increased.

\section{Family planning and dual method utilisation of women of reproductive age living with HIV}

Table 4.11 shows that the proportion of current family planning utilisation was 548 (83.8\%) with $95 \% \mathrm{Cl}$, which ranged from 81.2 to $86.8 \%$ among women living with HIV.

The prevalence of dual contraceptive utilisation was 425 (73.8\%) with $95 \% \mathrm{Cl}$ of 70 to $77.3 \%$, of which 343 $(80.7 \%)$ and $306(72 \%)$ were consistent and sustained use of the dual method among women living with HIV attending ART clinics.

The major reason reported for the dual method was dual protection (unwanted pregnancy/STI/HIV) which accounted for $386(90.8 \%)$ respondents, followed by advice given by healthcare providers during follow up $(n=20,4.7 \%)$.

This study revealed that the majority of women of reproductive age living with HIV had discussed dual method use with healthcare providers and their sexual partner; 543 (83.0\%) and 427 (65.3\%) respectively.

\section{Factors associated with current family planning utilisation}

Table 5 shows the logistic regression modelling that was undertaken to examine the net effects of a set of explanatory variables over the outcome variables and the odds ratios (OR) were adjusted for all other 
variables with $95 \%$ Cls. In this analysis, the outcome variables, current family planning utilisations, were dichotomised with " 1 " being utilised and " 0 " not being utilised.

Table 5

Factors associated with current family planning utilisation at multivariable logistic regression (AOR, 95\% $\mathrm{Cl}$ ) in Oromia, Ethiopia 2018

\begin{tabular}{|c|c|c|c|c|c|}
\hline \multicolumn{2}{|c|}{ Factors associated with current family planning } & \multicolumn{2}{|c|}{$\begin{array}{l}\text { Family planning } \\
\text { utilisation }\end{array}$} & \multirow[t]{2}{*}{$\begin{array}{l}\mathrm{P}- \\
\text { value }\end{array}$} & \multirow[t]{2}{*}{$\begin{array}{l}\mathrm{AOR}(95 \% \\
\mathrm{Cl})\end{array}$} \\
\hline & & Yes & No & & \\
\hline \multirow{2}{*}{$\begin{array}{l}\text { Discussed with } \\
\text { Healthcare }\end{array}$} & Yes & $485(74.2)$ & $58(8.9)$ & 0.000 & $\begin{array}{l}2.895(1.66- \\
.05)^{\star \star \star}\end{array}$ \\
\hline & No & $63(9.6)$ & $48(7.3)$ & $1: 00$ & \\
\hline \multirow[t]{2}{*}{$\begin{array}{l}\text { Knowledge towards modern } \\
\text { contraception methods }\end{array}$} & Good & $334(51.1)$ & $40(6.1)$ & 0.071 & $\begin{array}{l}1.593 \\
(0.96-2.64)\end{array}$ \\
\hline & Poor & $214(32.7)$ & $66(10.1)$ & $1: 00$ & \\
\hline \multirow[t]{2}{*}{ Number of sexual partners } & One & $524(81.7)$ & $84(13.1)$ & 0.029 & $\begin{array}{l}2.68(1.104- \\
6.50)^{\star}\end{array}$ \\
\hline & $\begin{array}{l}\text { Two \& } \\
\text { above }\end{array}$ & $15(2.3)$ & $18(2.8)$ & & \\
\hline \multirow{2}{*}{$\begin{array}{l}\text { last pregnancy } \\
\text { wanted/timed }\end{array}$} & Yes & $454(69.4)$ & $60(9.2)$ & $1: 00$ & \\
\hline & No & $94(14.4)$ & $46(7.0)$ & 0.000 & $\begin{array}{l}2.55(1.52- \\
4.28)^{\star \star \star}\end{array}$ \\
\hline \multirow[t]{3}{*}{ Partner HIV-positive: } & Yes & $427(65.3)$ & $54(8.3)$ & 0.000 & $\begin{array}{l}4.81(2.45- \\
9.41)^{\star \star \star}\end{array}$ \\
\hline & No & $87(13.3)$ & $18(2.8)$ & 0.000 & $\begin{array}{l}4.35(1.89- \\
9.95)^{\star \star \star \star}\end{array}$ \\
\hline & $\begin{array}{l}\text { Don't } \\
\text { know }\end{array}$ & $34(5.2)$ & $34(5.2)$ & $1: 00$ & \\
\hline \multirow[t]{2}{*}{ Disclose HIV status to family } & Yes & $442(67.6)$ & $57(8.7)$ & 0.047 & $\begin{array}{l}1.71(1.008- \\
2.91)^{\star}\end{array}$ \\
\hline & No & $106(16.2)$ & $49(7.5)$ & & \\
\hline
\end{tabular}

Two different models were fitted to investigate the factors predicting current family planning utilisation. In testing the fitness of the logistic model, if the $\mathrm{HL}$ goodness-of-fit test statistic is greater than 0.05 , the model is considered as a well-fitting model, implying that the estimates of the model fit the data at an acceptable level. Accordingly, the HL test for the following two models showed chi-square $p$-values $>0.05$, which proved the goodness-of-fit of the applied models for this study at $p=0.84$ for the current family planning utilisations model. 
Table 5 provides evidence based on the stated criteria that the factors that were identified through binary logistic regression were age, marital status, family monthly income, residence, discussion on dual method use with healthcare provider and with partner, knowledge family planning methods, number of sexual partners, previous pregnancy, future fertility desire, and partner's HIV status, respectively. These identified variables were entered into multiple logistic regression analyses.

Table 5 depicts that the respondents who had discussed family planning with healthcare providers during follow up were 2.9 times more likely to utilise family planning services as compared to those who had not. Women who had one or a single partner were at 2.7 times higher odds of family planning utilisation as compared to those who had two or more sexual partners. Moreover, women living with HIV whose last pregnancy was not intended were 2.6 times more likely to utilise family planning as compared to those who had intended their pregnancy.

The results further show that women who had a sexual partner with the same serostatus (concordant and discordant) were 4.8 times and 4.4 times more likely to utilise family planning services as compared to unknown serostatus partners. Those women of reproductive age who had disclosed their HIV result to their family were at 1.7 times higher odds of family planning utilisation as compared to those women who did not disclose their serostatus.

This study identified factors which increased the likelihood of modern contraception utilisation as including: discussion with healthcare providers regarding family planning; knowledge about modern family planning; the number of sexual partners; previous unplanned pregnancy; partner's HIV status; and disclosure status of HIV to their family. A partner's HIV status and disclosure status of HIV to their family meant higher odds of family planning utilisation among reproductive-aged women living with HIV in Oromia Region, Ethiopia.

\section{Factors associated with dual contraceptive utilisation}

Table 6 presents potential factors associated with dual contraceptive utilisation from both binary and multiple logistic regressions. Logistic regression modelling was undertaken to examine the net effects of a set of explanatory variables over the outcome variables, and the ORs were adjusted for all other variables with $95 \%$ Cls. In this analysis, the outcome variables, dual contraceptive utilisations were dichotomised with " 1 " being utilising and "0" being not utilising dual contraceptive methods. Two different models were fitted to investigate the factors predicting dual contraceptive utilisation.

Accordingly, the HL test for the following two models showed chi-square $\mathrm{p}$-values $>0.05$, which proved the goodness-of-fit of the applied models for this study at $p=0.74$ for dual contraceptive methods use. 
Table 6

Factors associated with dual contraceptive methods used at multivariable logistic regression (AOR, 95\% $\mathrm{Cl}$ ) in Oromia, Ethiopia 2018

\begin{tabular}{|c|c|c|c|c|c|}
\hline \multirow{2}{*}{\multicolumn{2}{|c|}{$\begin{array}{l}\text { Factors associated with dual contraceptive } \\
\text { utilisation }\end{array}$}} & \multicolumn{2}{|c|}{ Dual methods use } & \multirow{2}{*}{$\begin{array}{l}\mathrm{P}- \\
\text { value }\end{array}$} & \multirow{2}{*}{$\begin{array}{l}\mathrm{AOR}(95 \% \\
\mathrm{Cl})\end{array}$} \\
\hline & & Yes & No & & \\
\hline \multirow[t]{2}{*}{ Family planning counselled } & Yes & $281(48.8)$ & $45(7.8)$ & 0.024 & $\begin{array}{l}2.18(1.109- \\
4.27)^{\star}\end{array}$ \\
\hline & No & $144(25.0)$ & 106(18.4) & $1: 00$ & \\
\hline \multirow[t]{2}{*}{ Discussed with healthcare } & Yes & $400(69.4)$ & $100(17.4)$ & 0.006 & $\begin{array}{l}3.57(1.45- \\
8.83)^{\star \star \star}\end{array}$ \\
\hline & No & $25(4.3)$ & $51(8.9)$ & $1: 00$ & \\
\hline \multirow{2}{*}{$\begin{array}{l}\text { Received family planning counselling } \\
\text { on the efficacy of each method and side } \\
\text { effects }\end{array}$} & Yes & $382(66.3)$ & $83(14.4)$ & 0.000 & $\begin{array}{l}3.81(1.83- \\
7.92)^{\star \star \star}\end{array}$ \\
\hline & No & $43(7.5)$ & $68(11.8)$ & $1: 00$ & \\
\hline \multirow[t]{2}{*}{ last pregnancy wanted/timed } & Yes & $365(63.4)$ & $92(16.0)$ & $1: 00$ & \\
\hline & No & $60(10.4)$ & $59(10.2)$ & 0.001 & $\begin{array}{l}3.36(1.65- \\
6.86)^{\star \star \star \star}\end{array}$ \\
\hline \multirow{2}{*}{$\begin{array}{l}\text { ART providers knowledgeable and } \\
\text { comfortable for providing integrated } \\
\text { family planning/HIV services }\end{array}$} & Yes & $366(63.5)$ & 109(18.9) & 0.013 & $\begin{array}{l}2.898(1.26- \\
6.68)^{* \star}\end{array}$ \\
\hline & No & $59(10.2)$ & $42(7.3)$ & $1: 00$ & \\
\hline \multirow[t]{2}{*}{ Disclose HIV status to family } & Yes & $366(63.3)$ & $89(15.5)$ & 0.000 & $\begin{array}{l}3.57(1.79- \\
7.11)^{\star \star \star}\end{array}$ \\
\hline & No & $59(10.8)$ & $62(10.8)$ & $1: 00$ & \\
\hline
\end{tabular}

Keynote: ${ }^{* \star} \mathrm{p}<0.001,{ }^{*} \mathrm{p}<0.01,{ }^{*} \mathrm{p}<0.05 \mathrm{Cl}=$ confidence interval, $\mathrm{AOR}=$ adjusted odds ratio

As presented in Table 6, women who had attended family planning counselling during follow up were 2.18 times more likely to utilise dual contraceptive methods as compared to those who had not attended family planning counselling.

The reproductive-aged women who had discussions about family planning with their healthcare providers during follow up were also 3.6 times more likely to utilise dual method services.

Women who had received family planning counselling on the efficacy of each method, side effects and the mixed methods available to them were 3.8 times more likely to have higher odds of dual method utilisation as compared to women who had not received family planning counselling during follow-up.

Women of reproductive age who had a history of their last pregnancy being unwanted/unplanned were 3.36 times more likely to use dual methods as compared to a wanted/planned pregnancy. 
Women who had received services from knowledgeable and comfortable ART providers of integrated family planning/HIV services had 2.9 times higher odds of dual method utilisation as compared to those who were seen by unknowledgeable and uncomfortable ART providers.

Those women of reproductive age who had disclosed their HIV status to their family had 3.57 times higher odds of dual method utilisation as compared to those who had not disclosed their HIV status.

This study identified factors that increased the likelihood of dual contraception among reproductive-aged women living with HIV in Oromia Region, Ethiopia. These were found to be women who had discussed family planning with their healthcare provider and received family planning counselling about the efficacy of each method, the side effects and the mixed method available; women who received services from knowledgeable and comfortable ART providers for providing integrated family planning/HIV services; women who had experienced a previous unplanned pregnancy; a partner's HIV status and discloser of their HIV status to their family resulted in higher odds of dual contraception utilisation.

\section{Discussion}

With regard to the residential area, the majority of the respondents ( $n=518,79.2 \%)$, resided in urban areas, and $136(20.8 \%)$ lived in the rural area. The socioeconomic characteristics of the respondents were not different from the socioeconomic profile of Ethiopia. For example, in the general population of the same region, Christian denominations dominate and represent $65 \%$ of the population, and the largest ethnic group is Oromo, followed by Amhara which represent 64\% of the population (CSA 2016:33). The results are also similar in terms of the proportion of women who are currently married or living together with a partner $(65 \%)$ in the general population (CSA 2016:34).

Unintended pregnancy, family planning and dual contraceptive utilisation

This study identified that $21.4 \%$ of last pregnancies were unintended, which is consistent with the findings of a study conducted by Heffronet al (2010:261-267). The latter revealed that $21.2 \%$ of women were found to be pregnant during follow up; the pregnancy incidence rates were $16.3(95 \% \mathrm{Cl} 14.9-17.7)$ per 100 person-years. A study done in Mumbai, India, found that $16.6 \%$ of women had unintended pregnancies (Joshiet al2015:168). In contrast, a DHS conducted in 21 low- and middle-income countries revealed that the unmet need for family planning, a pregnancy risk, family planning methods, and use of postpartum family planning remain high at $61 \%$, while pregnancy risks can peak at 6 to 11 months after childbirth. The same study claims that women often rely on short-term methods only (51-96\%) (Mooreet al2015:31). Another study conducted on HIV-infected clients in Lusaka found that $49 \%$ reported that the pregnancy was unplanned (Hancock et al 2016:392). There are thus still gaps in the provision of care and continued limited availability of long-acting contraception for those who need it. This observation could be explained by the fact that, as this study shows, strengthening counselling on dual contraceptive method use for effective protection are crucial among these populations. Moreover, the issue of unintended pregnancies would be particularly important in terms of its contribution to new paediatric HIV 
infections. It is thus vital that there be reconsideration on dual method use for effective protection of unintended pregnancies among this population.

The current study indicated that $94.9 \%$ of women living with HIV were sexually active and $71.6 \%$ had used condoms, of which $61.9 \%$ always used condoms and $23.5 \%$ used condoms inconsistently. These findings were supported by a study conducted in Thailand which revealed that $82.3 \%$ of women were sexually active and $69.8 \%$ had used condoms (Munsakulet al 2016:8). This observation could be explained by the fact that, as this study shows, some sexually active reproductive-aged groups still ignore the modes of HIV infection.

The proportion of current family planning utilisation was $83.8 \%$ at $95 \% \mathrm{Cl}$ which ranged from 81.2 to $86.8 \%$ among women living with HIV. These findings were lower than what was reported in the previous study done in Thailand, which mentions that $96.3 \%$ of respondents had used a contraceptive method (Munsakulet al2016:8). Also, a study in Cambodia reflected that $68.5 \%$ of respondents used contraceptive methods (Nakaieet al2014:170), and South Ethiopia revealed that $77.4 \%$ used at least one form of family planning method (Feyssaet al 2015:3). These indicate the need for family planning among women living with HIV in family planning/HIV service settings. There is a need for increased comprehensive care in order to meet the women living with HIV's diverse need for integrated family planning/HIV services under one roof.

The prevalence of dual contraceptive utilisation was $73.8 \%$ with $95 \% \mathrm{Cl}$ of 70 to $77.3 \%$, of which $80.7 \%$ were consistent, and $72 \%$ were sustained users of the dual method in Oromia Region, Ethiopia. This prevalence was high compared to previous studies conducted among respondents with similar characteristics. For instance, in Mumbai, India, it was reported that $69 \%$ of respondents wished to use dual contraceptive methods for effective protection (Joshi et al 2015:168). In Thailand, 29.6\% used dual contraceptive methods (Munsakulet al 2016:8). Different countries had the following prevalence: in Cambodia, 17.5\% employed a dual contraceptive method (Nakaieet al2014:170); South-East Nigeria reported that $27.2 \%$ had practised dual method use, of which $26.8 \%$ used consistently in the preconception period but the majority (73.2\%) sometimes used in an inconsistent way (Lawaniet al2014:39); and a prospective study by Heffron et al (2010:621-628) revealed23.5\% dual contraceptive prevalence and consistent use. This discrepancy may be due to the fact that $83.0 \%$ of recent study respondents had discussed dual method utilisation with healthcare providers, and $65.3 \%$ with their sexual partner. Another possible contribution for this difference may due to service provision systems as evidenced from service providers and focal persons reporting that all health facilities offered sexual reproductive health services within HIV services with the same provider and offered on the same day, which accounts for $100 \%$ of respondents.

\section{Determinants of contraceptive utilisation among HIV- infected women}


This study identified factors that increased the likelihood of the use of modern contraceptives as women who had discussed family planning with healthcare providers; knowledgeability on modern family planning; number of sexual partners; unintended last pregnancy; sexual partner HIV status; and discloser status to their families. These findings are in line with some previous studies' findings which identified the determinants of family planning utilisation as obtaining family planning information from health facilities; awareness on MTCT; having a son; partner knowledge of HIV status; use of a contraceptive method prior to diagnosis of HIV; married or cohabiting couples; religion; age; wealth; education and having a child (Nakaie et al 2014:170; Laryeaet al 2014:26; Ngugiet al2014:S80).

This study identified factors that increased the likelihood of dual contraceptive use were women who had discussed family planning with healthcare providers; received family planning counselling on the efficacy of each method, side effects and the method mix available; had gotten services from knowledgeable and comfortable ART providers on integrated family planning/HIV services; had an unplanned previous pregnancy; had knowledge of their partner's HIV status; and discloser status of HIV to their family. These findings concur with some previous studies' which revealed determinants of dual contraceptive use as being female; receiving care; being aware of HIV status; being comfortable with asking a partner to use a condom; communication with a healthcare provider about family planning; household wealth; and HIVpositive women. These women were significantly more likely to use dual contraceptive methods (Munsakul et al 2016:4-5; Antelman et al 2015, Kimaniet al 2015:909). These findings demonstrate the importance of integrating reproductive health services into routine HIV care. In contrast, another study identified factors associated with decreased odds of dual method use as being of older age; being separated or/divorced; having fewer living children; and reporting that their partner wants a child (Munsakul et al 2016:4-5).

\section{Conclusion}

Modern family planning utilisation among women of reproductive age living with HIV was relatively high at $83.3 \%$ in the study area. The identified determinants of modern family planning utilisation were a discussion with healthcare providers in terms of family planning; knowledge about modern family planning; number of sexual partners; previous unplanned pregnancy; partner's HIV status; and disclosure status of HIV to their family. These determinants signified higher odds of family planning utilisation among women of reproductive age living with HIV in Oromia Region, Ethiopia.

The prevalence of dual contraceptive utilisation was $73.8 \%$, of which $80.7 \%$ were consistent and $72 \%$ were sustained users of the dual method in Oromia Region, Ethiopia. The identified factors associated with dual contraception method utilisations were discussion with healthcare providers regarding family planning; unplanned previous pregnancy; partner's HIV status; discloser status of HIV to their family; family planning counselling efficacy, and services from trained ART providers, respectively.

The current family planning utilisation among women of reproductive age living with HIV was 548 (83.8\%). The following were identified as determinants of current family planning among HIV-infected 
women in the area of study: open discussion on modern family planning utilisation with healthcare providers; being knowledgeable about modern family planning; number of sexual partners; previous unplanned pregnancy; partner's HIV status; and disclosure status of HIV to their family. The last two factors led to higher odds of family planning utilisation among women of reproductive age living with HIV in Oromia Region.

The study further established that contraception utilisation was influenced by the fact that $608(94.9 \%)$ respondents were sexually active during the last six months. Disclosure of HIV status added to the list whereby 589 (91.4\%) respondents had disclosed their HIV serostatus to a regular sexual partner and 499 (76.3\%) had disclosed to family.

\section{Recommendation}

Integrated family planning/HIV services contribute to the national family planning programmes to provide full access to a variety of contraceptive methods so that couples and individuals can obtain the method that best suits their needs. The main contribution of the study to the level of health policy is as follows:

- Increases consistent and sustainable dual contraceptive users among women of reproductive age living with HIV in Oromia Region, Ethiopia.

- Provide quality counselling to improve the knowledge of reproductive-aged and empowered women by service providers on the integrated family planning/HIV services.

- Healthcare providers should be trained, equipped, and encouraged to take ownership of the implementation of the reproductive-aged women-centred integrated family planning /HIV strategic plan.

- Strengthening implementation of integration of family planning and HIV services should lead to an increase in the utilisation of family planning, dual contraceptive methods, need for family planning being met, prevent repeated unwanted pregnancy, and offer HIV services. This will ultimately improve the quality of life of reproductive-aged women, the community, and families at large.

- Facilitate capacity building training for health professionals, health managers, women living with HIV and peer educators, including mother-to-mother support groups, so that all key actors are equipped with the necessary skills in sexual reproductive health services, family planning, and HIV.

- Innovate and scale-up best practices for the integration of maternal health service utilisation with HIV programme interventions.

- Establish a policy framework for institutional implementation, monitoring and sectorial coordination aimed at promoting and integrating sexual reproductive health services, family planning, and HIV focused on reproductive-aged people living with HIV. The framework can be tailor-made across sectors with the set goals of improving treatment outcomes and quality of life for people living with HIV, especial women of reproductive age living with HIV.

\section{Abbreviations}


AIDS Acquired Immune Deficiency Syndrome

ART Antiretroviral Therapy

AOR Adjusted Odd Ratio

CSA Central Statistical Agency

Cl Confidence Interval

COR Crude Odd Ratio

EDHS Ethiopian Demographic Health Survey

FHI Family Health International

FMOH Federal Ministry of Health

HIV Human Immuno-deficiency Virus

IUDs Intra Uterine Devices

OR Odds Ratio

ORHB Oromia Regional Health Bureau

PMTCT Prevention of Mother-to-Child transmission

STIs Sexually Transmitted Infections

UNAIDS United Nations Programme on HIV/AIDS

UNICEF United Nations International Children's Emergency Fund

UNISA University of South Africa

USAID United States Agency for International Development.

VCT Voluntary HIV counselling and testing

WHO World Health Organization

\section{Declarations}

\section{Acknowledgements}


We want to 'acknowledge University of South Africa (UNISA) for giving us this opportunity'. Our deepest gratitude goes to study participants, Ambo University, College of medicine and health sciences, Oromia Region Health Bureau, special zone surroundings of Finfinne Health office, supervisors and data collectors for their support. Finally, we would like to express my gratitude to all participants who volunteered participated in the study.

\section{Author Contributions}

All authors made substantial contributions to conception and design, acquisition of data, or analysis and interpretation of data; took part in drafting the article or revising it critically for important intellectual content; gave final approval of the version to be published; and agree to be accountable for all aspects of the work.

\section{Disclosure}

'The authors declare that they have no competing interests including financial or funding'.

\section{Funding}

The authors received no funding for this work.

\section{Competing Interests}

The authors declare there are no competing interests.

\section{References}

Antelman, G, Medley, A, Mbatia, R, Pals, S, Arthur, G, Haberlen, S\& Wanjiku, L. 2015. Pregnancy desire and dual method contraceptive use among people living with HIV attending clinical care in Kenya, Namibia and Tanzania. Journal of Family Planning and Reproductive Health Care, 41(1):e1-e1.

Atun, R, Lazarus, JV, Van Damme, W \& Coker, R. 2010. Interactions between critical health system functions and HIV/AIDS, tuberculosis and malaria programmes. Health Policy and Planning,25.i1-i3.

Bradley, H, Bedada, A, Tsui, A, Brahmbhatt, H, Gillespie, D \& Kidanu, A. 2008. HIV and family planning service integration and voluntary HIV counselling and testing client composition in Ethiopia. AIDS Care, 20(1):61-71.

Central Statistical Agency. 2016. Ethiopia demographic and health survey 2016: Key indicators report. Addis Ababa, Ethiopia, and Rockville, Maryland, USA: CSA and ICF.

Feyssa, MD, Tsehay, YB, \& Tadesse, AW. 2015. Unmet Need for Family Planning Among Women in HIV. AIDS Care at Antiretroviral therapy Clinic in South Ethiopia: A Challenge to Prevention of Mother to Child Transmission. Journal of AIDS and Clinical Research, 6(469):1-3. 
Hancock, NL, Chibwesha, CJ, Bosomprah, S, Newman, J, Mubiana-Mbewe, M, Sitali, E, S\& Chi, B.H. 2016. Contraceptive use among HIV-infected women and men receiving antiretroviral therapy in Lusaka, Zambia: A cross-sectional survey. BMC Public Health, 16(1):392.

Halperin, DT, Stover, J \& Reynolds, HW. 2009. Benefits and costs of expanding access to family planning programs to women living with HIV. Journal of AIDS, 23:S123-S130.

Heffron, R, Were, E, Celum, C, Mugo, N, Ngure, K, Kiarie, J \& Baeten, JM.2010. A prospective study of contraceptive use among African women in HIV-1 serodiscordant partnerships. Sexually Transmitted Diseases, 37(10):621-628.

Hladik, W, Stover, J, Esiru, G, Harper, M\& Tappero, J. 2009. The contribution of family planning towards the prevention of vertical HIV transmission in Uganda. PloS One, 4(11):e7691.

Hogan, MC, Foreman, KJ, Naghavi, M, Ahn, SY, Wang, M, Makela, SM \& Murray, CJ. 2010. Maternal mortality for 181 countries, 1980-2008: A systematic analysis of progress towards Millennium Development Goal 5. The Lancet, 375(9726):1609-1623.

Johnson, KB, Akwara, P, Rutstein, SO\& Bernstein, S. 2009. Fertility preferences and the need for contraception among women living with HIV: the basis for a joint action agenda. Journal of Acquired Immune Deficiency Syndromes, 23:S7-S17.

Joshi, B, Velhal, G, Chauhan, S, Kulkarni, R, Begum, S, Nandanwar, YS \& Dalal, A. 2015. Contraceptive use and unintended pregnancies among HIV-infected women in Mumbai. Indian Journal of Community Medicine: Official Publication of Indian Association of Preventive and Social Medicine, 40(3):168-171.

Kendall, T. and Danel, I., 2014. Research and evaluation agenda for HIV and maternal health in subSaharan Africa. Harvard School of Public Health: Boston, MA.

Kimani, J, Warren, C, Abuya, T, Mutemwa, R, Mayhew, S\& Askew, I. 2015. Family planning use and fertility desires among women living with HIV in Kenya. BMC Public Health, 15(1):909.

Laryea, DO, Amoako, YA, Spangenberg, K, Frimpong, E\& Kyei-Ansong, J. 2014. Contraceptive use and unmet need for family planning among HIV positive women on antiretroviral therapy in Kumasi, Ghana. BMC Women's Health, 14(1):126.

Lawani, LO, Onyebuchi, AK \& lyoke, CA. 2014. Dual method use for protection of pregnancy and disease prevention among HIV-infected women in South East Nigeria. BMC Women's Health, 14(1):39.

Mahy, M, Stover, J, Kiragu, K, Hayashi, C, Akwara, P, Luo, C\& Shaffer, N. 2010. What will it take to achieve virtual elimination of mother-to-child transmission of HIV? An assessment of current progress and future needs. Sexually Transmitted Infections, 86(Suppl 2):48-55. 
Moore, Z, Pfitzer, A, Gubin, R, Charurat, E, Elliott, L\& Croft, T. 2015. Missed opportunities for family planning: an analysis of pregnancy risk and contraceptive method use among postpartum women in 21 low-and middle-income countries. Contraception, 92(1):31-39.

Munsakul, W, Lolekha, R, Kowadisaiburana, B, Roongpisuthipong, A, Jirajariyavej, S, Asavapiriyanont, S \& Martin, M. 2016. Dual contraceptive method use and pregnancy intention among people living with HIV receiving HIV care at six hospitals in Thailand. Reproductive Health, 13:4-8.

Nakaie, N, Tuon, S, Nozaki, I, Yamaguchi, F, Sasaki, Y\& Kakimoto, K. 2014. Family planning practice and predictors of risk of inconsistent condom use among HIV-positive women on anti-retroviral therapy in Cambodia. BMC Public Health, 14(1):170.

Ngugi, EW, Kim, AA\& Nyoka, R. 2014. Contraceptive practices and fertility desires among HIV-infected and uninfected women in Kenya: results from a nationally representative study. Journal of Acquired Immune Deficiency Syndromes, 66(Suppl 1):S75-S81

Nutman, S, McKee, D\& Khoshnood, K. 2013. Externalities of prevention of mother-to-child transmission programs: A systematic review. AIDS and Behavior, 17(2):445-460.

Office Finfinne Special Zone. 2018. Sociodemographic data of Finfine special zone. Unpublished source.

O'Reilly, KR, Kennedy, CE, Fonner, VA \& Sweat, MD. 2013. Family planning counseling for women living with HIV: a systematic review of the evidence of effectiveness on contraceptive uptake and pregnancy incidence, 1990 to 2011. BMC Public Health, 13(1):935.

Orner, PJ, De Bruyn, M, Barbosa, RM, Boonstra, H, Gatsi-Mallet, J \& Cooper, D.D. 2011. Access to safe abortion: building choices for women living with HIV and AIDS. Journal of the International AIDS Society, 14(1):54, 1-9.

Reynolds, HW, Toroitich-Ruto, C, Nasution, M, Beaston-Blaakman, A\& Janowitz, B. 2008. Effectiveness of training supervisors to improve reproductive health quality of care: a cluster-randomized trial in Kenya. Health Policy and Planning, 23(1):56-66.

Scholl, E. and Cothran, D., 2011. Integrating family planning and HIV services. Programs in Kenya and Ethiopia lead the way.Case Study Series. Arlington, VA: USAID's AIDS Support and Technical Assistance Resources, AIDSTAR-One, Task Order 1.

Tudor-Car, L, Van-Velthoven, MHMMT, Brusamento, S, Elmoniry, H, Car, J, Majeed, A \& Atun R. 2011. Integrating prevention of mother-to-child HIV transmission (PMTCT) programmes with other health services for preventing HIV infection and improving HIV outcomes in developing countries (Review).Cochrane Database of Systematic Reviews, (6):9.

UNAIDS. 2014. The gap report. Joint United Nations Programme on HIV/AIDS. Geneva: WHO. 
UNAIDS. 2015. UNAIDS terminology guidelines. Geneva, Swaziland: UNAIDS.

Wanyenze, RK, Tumwesigye, NM, Kindyomunda, R, Beyeza-Kashesya, J, Atuyambe, L, Kansiime, A \& Mirembe, F. 2011. Uptake of family planning methods and unplanned pregnancies among HIV-infected individuals: a cross-sectional survey among clients at HIV clinics in Uganda. Journal of the International AIDS Society, 14(1):35.

WHO, USAID and FHI. 2009. Strategic considerations for strengthening the linkages between family planning and HIV/AIDS policies, programs, and services.

\section{Figures}

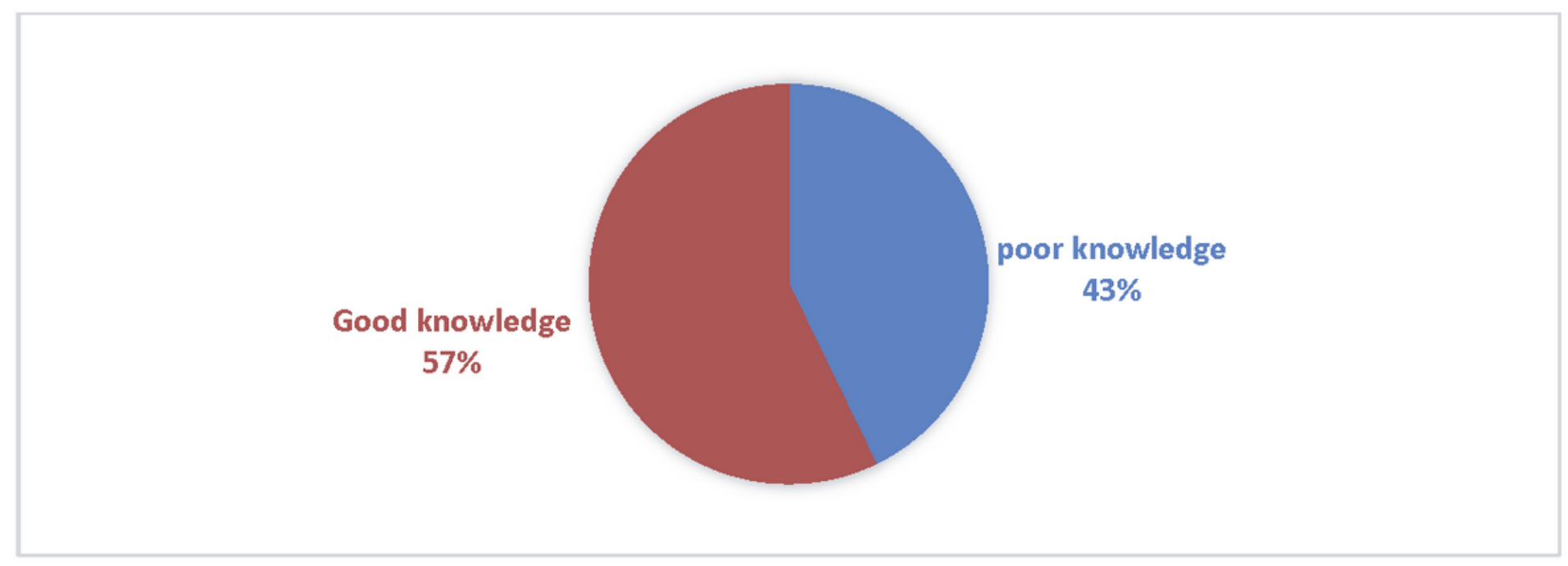

\section{Figure 1}

Knowledge about modern family planning methods of women of reproductive age living with HIV in Oromia, Ethiopia 2018 


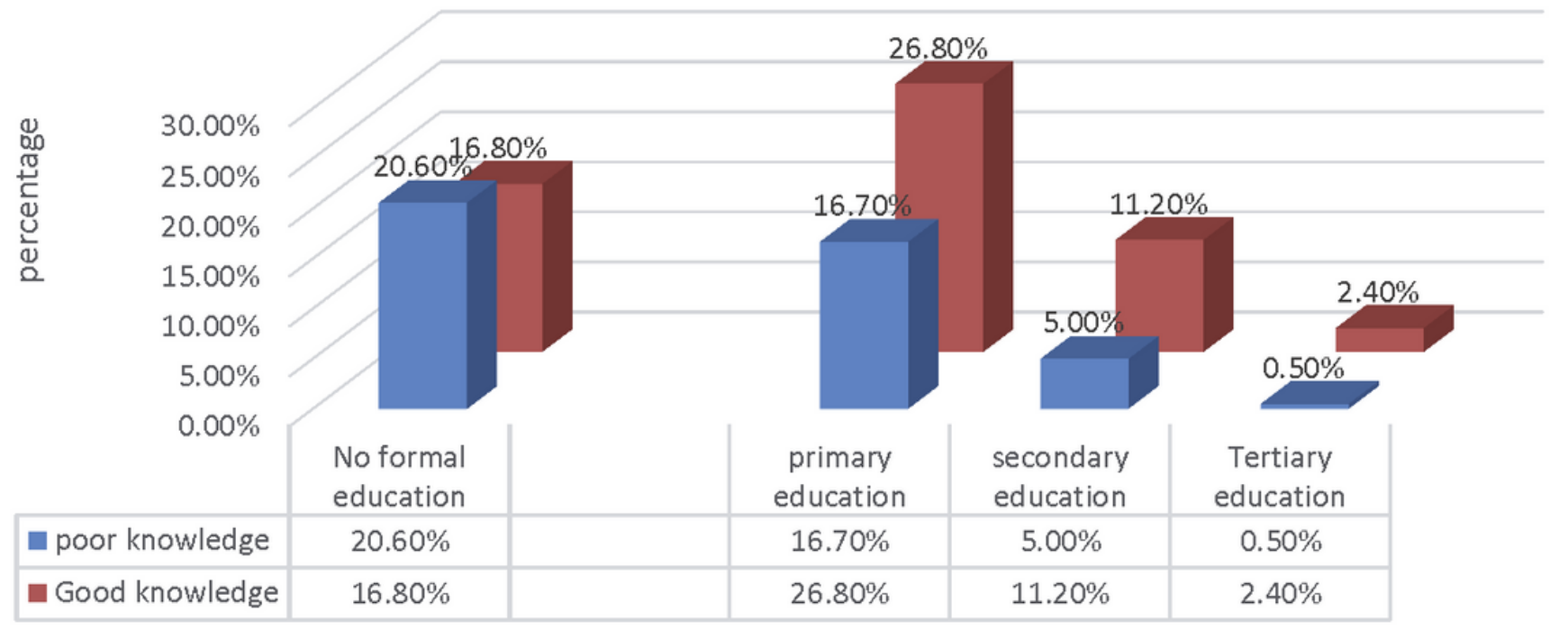

Figure 2

Educational levels of women by knowledge towards family planning methods of women of reproductive age living with HIV in Oromia, Ethiopia 2018

\section{Supplementary Files}

This is a list of supplementary files associated with this preprint. Click to download.

- QuestionnairesEnglishandAfanOromo.docx 